\title{
An investigation into the mechanism underlying enhanced hydrolysis of complex carbon in a biosulphidogenic recycling sludge bed reactor (RSBR)
}

\author{
JB Molwantwa ${ }^{2}, \mathrm{KJ}$ Whittington-Jones ${ }^{1}$ and PD Rose ${ }^{2}$ \\ ${ }^{1}$ Dept. Biochemistry, Microbiology and Biotechnology, PO Box 94, Rhodes University, Grahamstown 6140, South Africa \\ ${ }^{2}$ Environmental Biotechnology Research Unit, Rhodes University, Grahamstown 6140, South Africa
}

\begin{abstract}
The potential for using readily available and cost-effective complex carbon sources such as primary sewage sludge for a range of biological processes, including the bioremediation of acid mine drainage, has been constrained by the slow rate of solubilisation and low yield of soluble products, which drive the above mentioned processes. Previous research into the hydrolysis of complex organic matter, such as primary sludge, under biosulphidogenic conditions within a novel Recycling Sludge Bed Reactor (RSBR) demonstrated solubilisation in excess of $50 \%$. However, further investigation was required into the mechanism of this enhanced hydrolysis. The current study was aimed at confirming that hydrolysis is enhanced under biosulphidogenic conditions, and to obtain an estimate of the relative rates of hydrolysis using toluene as a specific metabolic inhibitor.

The solubilisation of primary sewage sludge under sulphate reducing conditions was conducted in controlled flask studies and previously reported findings of enhanced hydrolysis were confirmed. The maximum percentage solubilisation obtained in this study over a 10 -day period was $31 \%$ and $64 \%$ for the methanogenic and sulphidogenic systems respectively. By using toluene as an inhibitor of bacterial uptake of soluble carbohydrates, it was possible to determine the rate of production of various key products of the hydrolytic step. From the results of the current experiment, the rate of production of soluble carbohydrate, and therefore the rate of hydrolysis of complex carbohydrates, in terms of COD equivalents was estimated at $543 \mathrm{mgCOD} \cdot \ell^{-1} \cdot \mathrm{d}^{-1}$ and $156 \mathrm{mgCOD} \cdot \ell^{-}$ ${ }^{1} \cdot \mathrm{d}^{-1}$ under sulphidogenic and methanogenic conditions, respectively.
\end{abstract}

\section{Introduction}

Acid mine drainage (AMD) is a worldwide environmental hazard associated with current and past mining activities, and poses a serious threat to the quality of valuable surface water. Between 1988 and 1991, the mean volume of water being pumped from the East Rand mining basin was $65.4 \mathrm{M} \ell \cdot \mathrm{d}^{-1}$ (Scott, 1996). By 1997, Grootvlei was pumping $110 \mathrm{M \ell} \cdot \mathrm{d}^{-1}$ (Grootvlei, 1997). Currently, heavy metals are removed by a High Density Sludge (HDS) process and the mean iron concentration in the water being discharged into the Blesbok Spruit is less than $1 \mathrm{mg} \cdot \ell^{-1}$. However, at times, the concentration exceeds $44 \mathrm{mg} \cdot \ell^{-1}$. The high salt content of the water is still problematic, with sulphate being the dominant contaminant of concern in the effluents from South African mining operations (Pulles et al., 1995).

Attempts to reduce the pollution caused by AMD are aimed at increasing the $\mathrm{pH}$ of the water and reducing the concentrations of metals and salts to acceptable levels. Ideally, the methods used should be relatively inexpensive, easy to carry out and produce as little solid waste as possible (Gazea et al., 1996), and must be suitable for the remediation of large volumes of water. Popular non-biological treatment methods include lime treatment (Thompson, 1980; Barnes and Romberg, 1986) and the Bethlehem process (Henzen and Pieterse, 1978). Although chemical neutralisation is effective, the major drawbacks are the costs associated

This paper was originally presented at the 2004 Water Institute of South Africa (WISA) Biennial Conference, Cape Town, South Africa, 2-6 May 2004.

* To whom all correspondence should be addressed.

前+2746 603-8263; fax:+27

e-mail: K.Whittington-Jones@ru.ac·za with the purchase of reagents (lime), the transport and disposal of metal-laden sludge and plant construction (Gazea et al., 1996).

Biological treatment systems have a number of advantages over traditional chemical treatment methods, predominantly financial ones. Costs associated with chemical reagents, labour and sludge removal are negligible. Instead, costs are usually measured in terms of land (Gazea et al., 1996), making biological treatment particularly attractive in developing countries such as South Africa. Biological treatment includes treatment by wetlands and by bacterial consortiums, both in situ and in specially designed reactors.

Sulphate reducing bacteria (SRB) are found in a wide range of anaerobic environments, particularly in the anoxic sediments of freshwater (Elsgaard et al., 1994) and marine (Marty, 1981; Hines and Buck, 1982) systems. The potential involvement of these microbes for the bioremediation of AMD and other sulphate- and metal-rich industrial effluents has also been realised (Tuttle et al., 1969, Maree and Strydom, 1985; Maree et al., 1986; Maree et al., 1987; Maree and Hill, 1989; Widdel and Hansen, 1992).

As is the case with the construction of artificial wetlands, one of the most important obstacles to the implementation of biological treatment systems on a large-scale is the availability and cost of a suitable carbon source and electron donor. Under anaerobic conditions, SRB are able to oxidise a range of organic acids such as lactate, acetate and propionate as well as hydrogen. Sulphate is then used as an electron acceptor, and is reduced to sulphide (Widdel, 1988). Simple electron donors, including methanol and ethanol, are relatively expensive and are therefore not suitable for use in developing countries. A wide variety of relatively inexpensive agricultural and domestic wastes have been investigated as possible alternative sources of soluble carbon. These have included cattle waste (Ueki et al., 1988), molasses (Maree and Hill, 1989), 
lactate and cheese whey (Oleszkiewics and Hilton, 1986, Herrera et al., 1991), producer gas (Du Preeze et al., 1992) and sewage sludge (Butlin et al., 1956; Burgess and Wood, 1961; Conradie and Grutz, 1973).

The limited success using primary sludge (PS) as a carbon source for a range of biological processes, including sulphate reduction, may be ascribed to the inefficient hydrolysis of the complex substrate. Hydrolysis, the initial cleavage step, is widely considered to be rate-limiting (Eastman and Ferguson, 1981; San Pedro et al., 1994; Eliosov and Argaman, 1995; El-Fadel et al., 1996; Vavilin et al., 1996; Penaud et al., 1997). Yields of soluble products, such as volatile fatty acids (VFA) and soluble sugars, can be affected by both environmental and operational parameters, and are usually low, with the average being less than $20 \%$ (WhittingtonJones, 2000). The maximum reported yield from hydrolysis of PS under methanogenic conditions is approximately $35 \%$ at $24^{\circ} \mathrm{C}$ (Hatziconstantinou et al., 1996).

Until recently, the digestion of complex organic matter under bio-sulphidogenic conditions has been largely ignored, although research has shown that the mineralisation of lignocellulosic solid waste was improved significantly in the presence of biological sulphate reduction (Kim et al., 1997; Pareek et al., 1998). While investigating the applicability of an integrated biological treatment system for the remediation of tannery effluent, Dunn et al. (1998) commented that the solubilisation of complex organic matter in natural ponds appeared to be "enhanced" under biosulphidogenic conditions. It was proposed that the underlying mechanism involved the continuous settling of complex organic matter to the sulphidogenic sediment on the base of the ponds, where initial hydrolysis took place. Agitation of the sediment layer resulted in the release of the soluble products for consumption by SRB and other heterotrophic microbes, and the remaining undigested material was resuspended and recirculated between the sediment and the water body until only the recalcitrant fraction remained. Subsequent studies into the mechanism of enhanced hydrolysis of complex carbon under biosulphidogenic conditions indicated that fracturing of larger sludge flocs was facilitated in the presence of sulphide and it was proposed that this fracturing process was central to increased yields of soluble product observed(WhittingtonJones, 2000; Whittington-Jones et al., 2002). This understanding was used to develop the Recycling Sludge Bed Reactor (RSBR), and tests on both laboratory- and pilot-scale indicated yields in excess of $50 \%$.

This paper reports on laboratory experiments aimed at confirming that hydrolysis is enhanced under biosulphidogenic conditions, and to obtain an estimate of the relative rates of hydrolysis using toluene as a specific metabolic inhibitor.

\section{Methods and materials}

\section{Confirmation of enhanced hydrolysis}

The experiment was conducted in triplicate in $500 \mathrm{~m} \ell$ conical flasks. In order to monitor the removal of carbon under sulphidogenic and methanogenic conditions, flasks were inoculated $(10 \%$ by volume) with populations of SRB and MPB, respectively, obtained from $5 \ell$ cell culture units that had been operating for 3 months prior to the current experimental programme. Sieved (2mm mesh) primary sludge (PS) obtained from Grahamstown Municipal Works was used as a carbon source and was diluted with distilled water to a final COD of $2000 \mathrm{mg} \cdot \ell^{-1}$. The initial sulphate concentration within the sulphidogenic flasks was increased to $2000 \mathrm{mg} \cdot \ell^{-1}$ using analytical-grade $\mathrm{Na}_{2} \mathrm{SO}_{4}$ (Merck), thus giving a COD:SO ratio of
1:1. The neck of each flask was sealed with a rubber stopper but gas was allowed to escape through a u-tube filled with zinc acetate. All flasks were incubated in a constant environment (CE) room at $25^{\circ} \mathrm{C}$ in the dark and shaken on a Labcon desktop shaker at 100rpm for the duration of the experiment. In order to prevent ingress of oxygen into the flasks during sampling, samples were forced out of the flasks under positive pressure using nitrogen gas. The contents of the flasks were monitored every 2 days until no further change in the COD was evident.

\section{Inhibitor studies}

The only source of reducing sugars in the current system was via the hydrolysis of PS but in order to determine the rate at which these products are produced, and therefore obtain a more accurate estimate of the rate of hydrolysis, further processing of the products must be inhibited. Other authors (Boschker et al., 1995) reported that the inhibition of sugar uptake by bacteria could be achieved using toluene, and that this does not affect extracellular hydrolysis of polysaccharides in the sample. The experimental setup was exactly as described above. The two controls (methanogenic and sulphidogenic) and the two experiments to which toluene had been added (methanogenic + toluene and sulphidogenic + toluene) were set up in triplicate in $500 \mathrm{~m} \ell$ flasks. Each flask was innoculated with $10 \%$ sludge from either the methanogenic or sulphidogenic stock culture. $400 \mathrm{~m} \ell$ of fresh sieved (2 mm mesh) PS was then added to each flask as the sole carbon source. The flasks were placed on a desktop shaker (100 rpm) and were allowed to acclimate for 2 days in a $\mathrm{CE}$ room at $25^{\circ} \mathrm{C}$ before the addition of 15 $\mathrm{m} \ell$ of toluene (to give a final concentration of $3 \% \mathrm{vol} / \mathrm{vol}$ ) to the six experimental flasks. The remaining six flasks served as the sulphidogenic and methanogenic controls and had no toluene added to them. Samples were collected (described earlier) at hourly intervals for 8 hours (as the inhibition of toluene on the bacteria only lasts for 7-8 hours). The first sample was taken at $\mathrm{t}=0$ after which toluene was immediately added to the experimental flasks.

\section{Analytical procedures}

All samples were analysed in triplicate using the procedures outlined below.

A Merck $^{\circledR}$ spectroquant test kit was used to determine the $\mathrm{COD}_{\text {total }}$ and $\mathrm{COD}_{\text {filtered }}$ of each sample, where $\mathrm{COD}_{\text {filtered }}$ was taken to represent the soluble COD fraction. Thus, the remaining fraction, $\mathrm{COD}_{\text {particulate }}$, was calculated as $\mathrm{COD}_{\text {total }}-\mathrm{COD}_{\text {filtered }}$. Prior to analysis, all samples were acidified with $32 \% \mathrm{HCl}$ to $\mathrm{pH} 2$ and agitated for 1 minute in order to eliminate any sulphide interference with the assay (Whittington-Jones 2000). In many cases, the $\mathrm{COD}_{\text {total }}$ exceeded the range of the test kit and these samples were then diluted appropriately with distilled water. For the determination of $\mathrm{COD}_{\text {filtered }}$, samples were centrifuged in an Eppendorf 5415D centrifuge (rotor F45-24-11) at 3000 rpm for 5 minutes, and the supernatant was then passed through a $0.45 \mu \mathrm{m}$ nylon filter. The COD of the filtrate was then taken to represent the soluble COD fraction. A blank was prepared using deionised water in place of the sample.

Sulphate concentrations were determined using an HPLC anion method applying a model 510 Waters HPLC and model 430 Waters conductivity detector fitted with a Hamilton PRPX 100 150X4.1 mm column. As with COD analysis, all samples were acidified and centrifuged as described above prior to analysis. A ten-fold dilution of the sample was prepared using milli-Q water and then filtered through a $0.45 \mu \mathrm{m}$ nylon filter before passing it through two Waters sep-pak® light C18 cartridges to remove the 


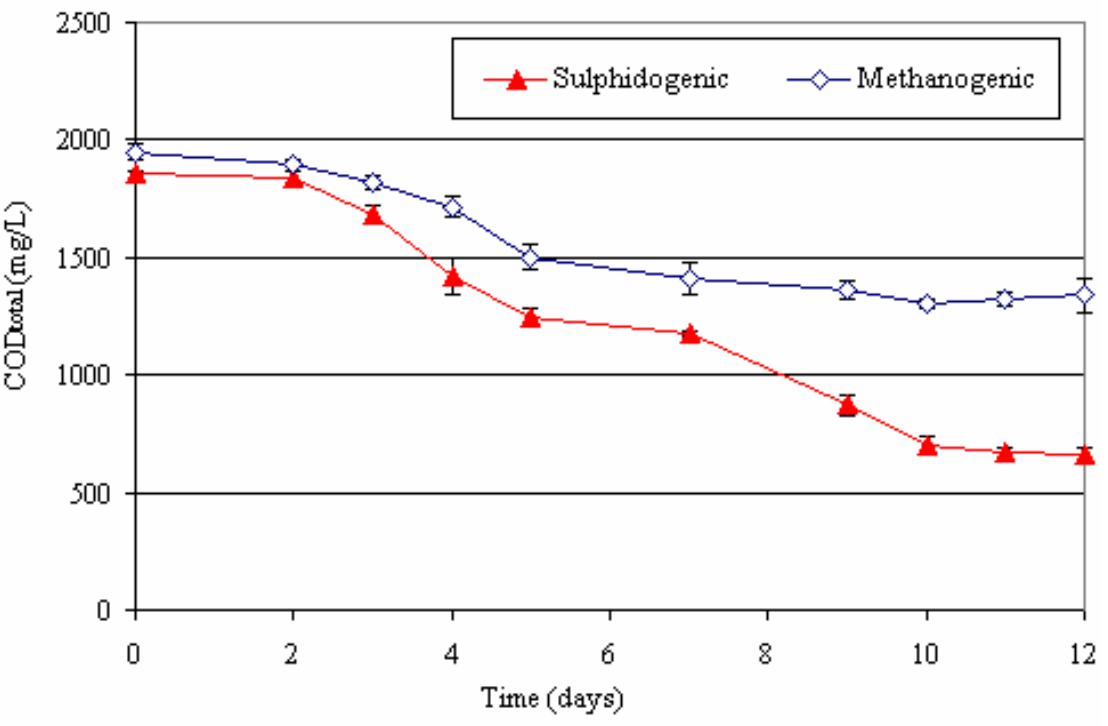

organic contaminants. The samples were then injected into the HPLC and run at $2 \mathrm{~m} \ell \cdot \mathrm{min}^{-1}$. A $100 \mathrm{mg} \cdot \ell^{-1} \mathrm{Na}_{2} \mathrm{SO}_{4}$ standard was prepared in order to determine the retention time of the sulphate peak as well as to standardise the accuracy of the instrument. The sulphate concentrations were determined using a standard curve also prepared using analytical grade $\mathrm{Na}_{2} \mathrm{SO}_{4}$.

For determination of sulphide, samples were collected in tubes containing $100 \mu \ell$ of a $0.1 \mathrm{M}$ zinc acetate solution to prevent sulphide from escaping, and then analysed according to the method of Du Bois et al. (1956). A standard curve was created using analytical grade sodium sulphide.

Statistica Version 6.0 was used for statistical analysis of the recorded data.

\section{Results and discussion}

The initial experiment of this study was aimed at confirming that the degradation of complex organic matter was enhanced under biosulphidogenic conditions. Results from flask studies (Figure 1) conducted over a period of 12 days showed that the mean removal of $\mathrm{COD}_{\text {total }}$ under sulphidogenic conditions (64.27\%) was significantly higher than under methanogenic conditions (31.28\%) (ANOVA, $\mathrm{p}<0.001, \mathrm{n}=3$ ). The mean COD in both systems decreased until day 5 with a $23 \%$ and $33 \%$ removal in the methanogenic and biosulphidogenic flasks, respectively. Between day 5 and the end of the experiment, further removal of COD under methanogenic conditions was limited. Thus, while digestion in the methanogenic system exhibited a rapid and slow phase, hydrolysis within the sulphidogenic system exhibited 2 rapid phases separated by a period where very little removal was observed (days $5-7$ ). After day 7 , the COD decreased from $1180 \mathrm{mg} \cdot \ell^{-1}$ to $663 \mathrm{mg} \cdot \ell^{-1}$ on day 12. This two-step hydrolysis may be a reflection of two classes of organic matter within the PS i.e. readily and slowly degradable material. Furthermore, the results suggest that while the readily degradable fraction is removed under both electron-acceptor conditions, a larger proportion of the less readily available material is only available under sulphidogenic conditions. This may be as a result of direct utilisation of the material by the bacterial consortium or as a result of enhanced hydrolysis due to the effects of the sulphide. Although the RSBR was designed to facilitate enhanced hydrolysis, this result indicates that similar results are obtained in stirred flask systems. Based on the above results, the mean rate of
$\mathrm{COD}_{\text {total }}$ removal in the methanogenic system $\left(50 \mathrm{mgCOD} \cdot \ell^{-1} \cdot \mathrm{d}^{-1}\right)$ was approximately half that of the sulphidogenic system (102 $\left.\operatorname{mgCOD} \cdot \ell^{-1} \cdot \mathrm{d}^{-1}\right)$. As these rates were calculated using $\operatorname{COD}_{\text {total }}$, they do not present an accurate estimate of the rate of hydrolysis but do support the preliminary findings of Molipane (1999) and Whittington-Jones (2000), who demonstrated enhanced degradation of PS under sulphate reducing conditions compared to nonsulphate reducing conditions. Importantly, the results showed that while approximately 68\% of the COD in PS was not readily solubilised under methanogenic conditions, only 35\% was not used in sulphidogenic systems.

The second stage of the study was aimed at determining firstly the rates of hydrolysis by following the production of soluble products in the two model systems. Based on the results from preliminary studies, it was decided to limit subsequent experiments to 7 days as the removal of organic matter in methanogenic systems was insignificant after this period. The experimental setup was exactly the same as described above. The concentration of sulphide increased in the sulphidogenic system to reach a maximum concentration of $533 \mathrm{mg} \cdot \ell^{-1}$ on day 4, indicating that the SRB population was active. However, sulphide was also produced in the methanogenic flasks, reaching a maximum concentration of $109 \mathrm{mg} \cdot \ell^{-1}$ on day 5 . Based on the removal of COD

(Fig. 2), the mean hydrolysis rates for methanogenic and sulphidogenic systems were calculated as $88 \operatorname{mgCOD} \cdot \ell^{-1} \cdot \mathrm{d}^{-1}$ and $137 \mathrm{mgCOD} \cdot \ell^{-1} \cdot \mathrm{d}^{-1}$ respectively. These data, together with those obtained during the 12-day experiment indicate that both the degree and rate of solubilisation of complex carbon are improved in the presence of biosulphidogenic activity.

In both systems, $\mathrm{COD}_{\text {fittered }}$ accumulated over the 7-day period, with concentrations rising by $19 \%$ and $49 \%$ in the methanogenic and sulphidogenic systems, respectively (data not shown). As the concentration of soluble product at any one time represented the difference between the rate of production and rate of utilisation, the observed increase may have been as a result of slow utilisation or relatively rapid production. The rapid accumulation of soluble product in the sulphidogenic systems was unexpected as SRB are known to utilise a wider range of VFA and reducing sugars than methanogenic populations (Aguilar et al., 1995). This would, however, explain the accumulation in the methanogenic system as MPB are known to use acetate in preference to longer chain fatty acids which, if produced, would then have accumulated. This 


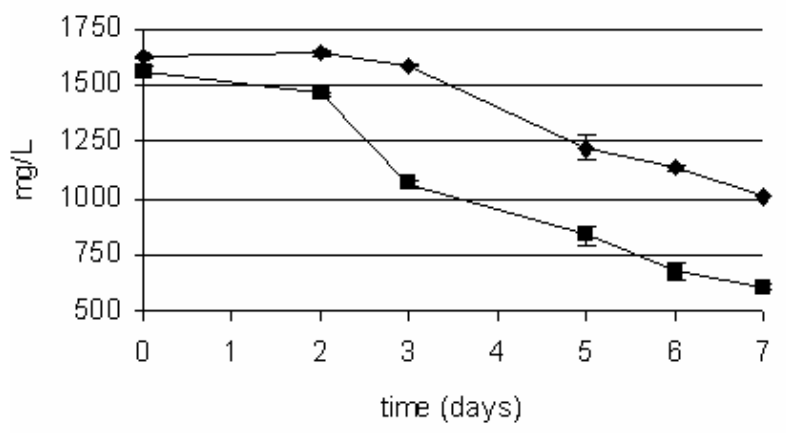

$\longrightarrow$ methanogenic —- sulphidogenic

Figure 2

Mean $C O D_{\text {particulate }}$ concentrations over the 7-day experimental under methanogenic and sulphidogenic conditions $(n=3)$

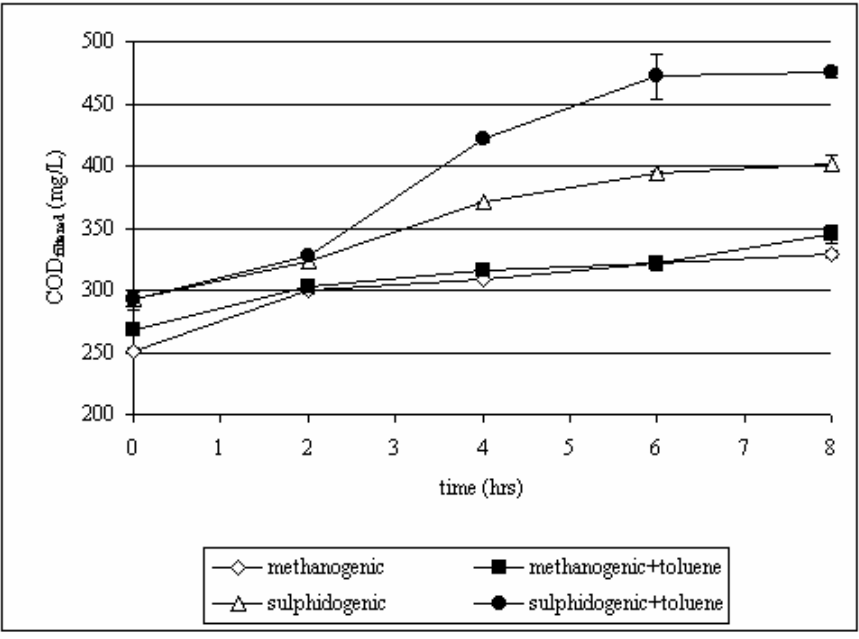

Figure 3

Concentrations of $\mathrm{COD}_{\text {fitered }}$ in methanogenic and sulphidogenic flasks after toluene was used to inhibit the uptake of soluble carbohydrates $(n=3)$

accumulation of soluble product would have also have explained the gradual decrease in the mean $\mathrm{pH}$ in the methanogenic system from $\mathrm{pH} 7$ on day 0 to mean of 6.7 over the 7-day period. Production of alkalinity during biological sulphate reduction (Widdel, 1988; Widdel and Hansen, 1992) would have accounted for the increase in the $\mathrm{pH}$ of the sulphidogenic systems despite the apparent accumulation of product.

Due to the relative nature of the above data i.e. production and consumption of soluble organic material, further studies were required. The application of selective metabolic inhibitors enabled accurate determination of the rate of production of soluble organic material. This data then enabled a more accurate assessment of the rate of hydrolysis under both electron acceptor conditions.

\section{Inhibitor studies}

While the inhibition of sugar uptake had a significant effect on the accumulation of $\mathrm{COD}_{\text {filtered }}$ (Fig. 3) in the sulphidogenic system (ANOVA, $\mathrm{p}<0.05, \mathrm{n}=3$ ), this was not the case for the methanogenic systems (ANOVA, $\mathrm{p}>0.05, \mathrm{n}=3$ ).

The overall percentage increase in $\mathrm{COD}_{\text {filtered }}$ in the tolueneinhibited sulphidogenic system was $61 \%$ with an increase of $34 \%$ in the sulphidogenic control (Fig. 3) while the methanogenic system exhibited an overall increase of $\mathrm{COD}_{\text {filtered }} 30 \%$ for the treatment (under toluene inhibition) and an increase of $31 \%$ in the control. This result was in line with the results obtained in the previous 7-day experiment where the concentration of $\mathrm{COD}_{\text {filtered }}$ in the sulphidogenic system increased by $49 \%$ in the absence of inhibitors, and implied that a significant proportion of the accumulated product in the earlier experiment was as a result of the hydrolysis of complex carbohydrates. From the results of the current experiment, the rate of production of soluble carbohydrate, and therefore the rate of hydrolysis of complex carbohydrates, in terms of COD equivalents was estimated at $543 \mathrm{mgCOD} \cdot \ell^{-1} \cdot \mathrm{d}^{-1}$ and $156 \mathrm{mgCOD} \cdot \ell^{-1} \cdot \mathrm{d}^{-1}$ under sulphidogenic and methanogenic conditions, respectively. These values are higher than those based on the removal of $\mathrm{COD}_{\text {particulate }}$ but support the hypothesis that hydrolysis is enhanced in the presence of biosulphidogenic activity. The significant difference between the sulphidogenic control and the treatment indicated that the rate of utilisation of soluble sugars was rapid under these conditions.

The implications of these observations are that production of soluble carbohydrates (that would contribute to the soluble COD fraction) under methanogenic conditions was low relative to production when sulphate was present as an electron acceptor. Furthermore, the lack of any significant difference between the methanogenic treatment and control indicated that direct uptake of soluble carbohydrates under methanogenic conditions was negligible while the opposite was true for sulphidogenic systems. As toluene targets the uptake of soluble carbohydrates, the above data is thought to be an accurate indication of the breakdown of source molecules i.e. complex carbohydrates in PS. Although it was speculated that accumulation of $\mathrm{COD}_{\text {filtered }}$ was due to elevated levels of reducing sugars, this remained to be tested.

When considered as a whole, the above data supports the findings of Dunn (1998) and Whittington-Jones (2000) who provided initial indications that the hydrolysis of complex organic matter, and specifically carbohydrates, was enhanced in biosulphidogenic environments. Not only is the yield of soluble product significantly increased, but based on the removal of $\mathrm{COD}_{\text {total }}$, $\mathrm{COD}_{\text {particulate }}$ and the production of soluble carbohydrates in the presence of an inhibitor the rate of hydrolysis of the carbohydrate fraction was approximately 2.5 times faster. Importantly, estimates of the hydrolysis rate does seem to depend on how it was calculated, and while it is possible to speculate on the rate of hydrolysis of non-carbohydrate fractions eg. proteins, this would need to be the subject of further investigation.

\section{Conclusion}

AMD is a global environmental problem and the use of biological systems for the remediation of this threat to freshwater resources is promising. However, the provision of a suitable carbon source to drive the process still remain the biggest obstacle although the current studies on the RSBR indicate that yield of soluble organic products can be improved when complex material such as PS is digested in the presence of active biological sulphate reduction. Although the phenomenon of enhanced hydrolysis has been confirmed, at this early stage the underlying mechanism is not well understood and will be the subject of further investigation.

\section{References}

AGUILAR A, CASA C and LEMA JM (1995) Degradation of volatile fatty acids by differently enriched methanogenic cultures: Kinetics and inhibition. Water Res. 29 (2) 505-509. 
BARNES HL and ROMBERG SB (1986) Chemical aspects of acid mine drainage. J. Water Pollut.Control. Fed. 40 371-384.

BOSCHKER HT, BERTILSSONSA, DEKKERS EMJ and CAPPENBERG TE (1995) An inhibitor-based method to measure initial decomposition of naturally occurring polysaccharides in sediments. Appl. Environ. Microbiol. 61 2186-2192.

BURGESS SG and WOOD LB (1961) Pilot plant studies in production of sulphur from sulphate-enriched sewage sludge. J. Sci. Food Agric. 12 326-341.

BUTLIN KR, SELWYN SC and WAKERLEY DS (1956) Sulphide production from sulphate-enriched sewage sludges. J. Appl. Bacteriol. 19 3-15.

CONRADIE PJA and GRUTZ PWE (1973) The Treatment of Acid Mine Waste in a Mixture with Sewage Sludge in an Anaerobic Digester. Report to the Chamber of Mines (File No. w6/534/3). National Institute for Water Research, Pretoria.

DU PREEZ LA and MAREE JP (1994) Pilot-scale biological sulphate and nitrate removal utilizing producer gas as an energy source. Water Sci. Technol. 30 275-285.

DU PREEZ LA, ODENDAAL JP, MAREE JP and PONSONBY M (1992) Biological removal of sulphate from industrial effluents using producer gas as an energy source. Environ. Technol. 13 875-882.

DUBOIS M, GILLES KA, HAMILTON JK, REBERS PA and SMITH F (1956) Colorimetric method for determination of sugars and related substances. Anal. Chem. 28 350-356.

DUNN K (1998) The Biotechnology of High Rate algal Ponding Systems in the Treatment of Saline Tannery Wastewaters. PhD Thesis. Rhodes University, Grahamstown, South Africa.

EASTMAN JA and FERGUSON JF (1981) Solubilization of particulate organic carbon during the acid phase of anaerobic digestion. J. WPCF 53 352-366.

EL-FADEL M, FINDIKAKIS AN and LECKIE JO (1996) Temperature effects in modelling solid waste biodegradation. Environ. Technol. 17 915-935.

ELIOSOV B and ARGAMAN Y (1995) Hydrolysis of particulate organics in activated sludge systems. Water Res. 29 155-163.

ELSGAARD L, PRIEUR D, MUKWAYA GM and JORGENSEN BB (1994) Thermophilic sulphate reduction in hydrothermal sediment of lake Tanganyika, East Africa. Appl. Environ. Microbiol. 60 14731480.

GAZEA B, ADAM K and KONTOPOULOS A (1996) A review of passive systems for the treatment of acid mine drainage. Miner. Eng. 9 23-42.

GROOTVLEI (Pty) MINES Ltd (1997) Monitoring of the Blesbok Spruit: Impacts of treated mine effluents from Grootvlei Mine (Company report).

HATZICONSTANTINOU GJ, YANNAKOPOULOS P and ANDREADAKIS A (1996) Primary sludge hydrolysis for biological nutrient removal. Water Sci. Technol. 34 417-423.

HENZEN MR and PIETERSE MJ (1978) Acid mine drainage in the Republic of South Africa. Prog. Water Technol. 9 981-1000.

HERRERA LJ, HERNÀNDEZ P, RUÍZ and GANTENBEIN S (1991) Desulfovibrio desulfuricans growth kinetics. Environ. Toxicol. Water Qual. 6 225-238.

HINES ME and BUCK JD (1982) Distribution of methanogenic and sulfate-reducing bacteria in near-shore marine sediments. Appl. Environ. Microbiol. 43 447-453.

KIM SK, MATSUI S, PAREEK S, SHIMIZU Y and MATSUDE T (1997) Biodegradation of recalcitrant organic matter under sulphate reducing and methanogenic conditions in the landfill column reactors. Water Sci. Technol. 36 91-98.
MAREE JP and HILL E (1989) Biological removal of sulphate from industrial effluents and concomitant production of sulphur. Water Sci. Technol. 21 265-276.

MAREE JP and STRYDOM WF (1985) Biological sulphate removal in an upflow packed bed reactor. Water SA 19 101-106.

MAREE JP, GERBER A and HILL E (1987). An integrated process for biological treatment of $\mathrm{SO}_{4}$-containing industrial effluents. J. WPCF 59 1069-1074.

MAREE JP, GERBER, A and STRYDOM WF (1986) A biological process for sulphate removal from industrial effluents. Water SA 12 139-144.

MARTY D (1981) Distribution of different anaerobic bacteria in Arabian Sea sediments. Mar. Biol 63 277-281.

MOLIPANE NP (1999) Biological Sulphate Reduction Utilising Hydrolysis of a Complex Carbon Source. M.Sc. Thesis, Rhodes University, Grahamstown, South Africa.

OLESZKIEWICZ JA and HILTON BL (1986) Anaerobic treatment of high sulphate wastes. Can. J. Civ. Eng. 13 423-428.

PAREEK S, KIM SK, MATSUI S and SHIMIZU Y (1998) Hydrolysis of (ligno) cellulosic materials under sulfidogenic and methanogenic conditions. Water Sci. Technol. 38 193-200.

PENAUDV, DELGENES JP, TORRIJOS M, MOLETTAR, VANHOUTTE B and CANS P (1997) Definition of optimal conditions for the hydrolysis and acidogenesis of pharmaceutical microbial biomass. Process Biochem. 32 515-521.

PULLES W, HOWIE D, OTTO D and EASTON J (1995) A Manual on Mine Water Treatment and Management Practices in South Africa. Water Research Commission, Report No. TT 80/96.

SAN PEDRO DC, MINO T and MATSUO T (1994) Evaluation of the rate of hydrolysis of slowly biodegradable COD (SBCOD) using starch as a substrate under anaerobic, anoxic and aerobic conditions. Water Sci. Technol. 30 191-199.

SCOTT R (1995) Flooding of Central and East Rand Gold Mines: An Investigation into Controls over the Inflow Rate, Water Quality and the Predicted Impacts of Flooded Mines. Water Research Commission, Report No. 486/1/95.

THOMPSON JG (1980) Acid mine waters in South Africa and their amelioration. Water SA 6 130-134.

TUTTLE JH, DUGAN PR and RANDLES CI (1969) Microbial dissimilatory sulfur cycle in acid mine water. J. Bacteriol. 97 594-602.

UEKI K, KOTAKA K, ITOH K and UEKI A (1988) Potential availability of anaerobic treatment with digester slurry of animal waste for the reclamation of acid mine water containing sulphate and heavy metals. J. Ferment. Technol. 66 43-50.

VAVILIN VA, RYTOV SV and LOKSHINA LY (1996) A description of hydrolysis kinetics in anaerobic degradation of particulate organic matter. Bioresource Technol. 56 229-237.

WHITTINGTON-JONES K (2000) Sulphide-Enhanced Hydrolysis of PSS: Implications for the Bioremediation of Sulphate-Enriched Wastewaters. PhD Thesis, Rhodes University, Grahamstown, South Africa.

WHITTINGTON-JONES KJ, CORBETT CJ and ROSE PD (2002) The Rhodes 'BioSURE' Process. Part 2: Enhanced Hydrolysis of Organic Carbon Substrates - Development of the Reciprocating Sludge Bed Reactor. Water Research Commission Report, South Africa.

WIDDEL F and HANSEN TA (1992) Dissimilatory sulphate or sulphur reducing bacteria. In: A Ballows, HG Truper, M Dworkin, W Harder and K Schleifer (eds.) The Prokaryotes, Volume 1. Springer-Verlag, Berlin. 583 pp.

WIDDEL F (1988) Microbiology and Ecology of sulfate- and sulfurreducing bacteria. In: JB Zehnder (ed.) Biology of Anaerobic Microorganisms. John Wiley and Sons, New York. 469 pp. 